\title{
Worksite Follow-Up and Engagement Strategies for Initiating Health Risk Behavior Changes
}

\author{
Walter Gregg, MA, MPH \\ Andrea Foote, PhD, MA \\ John C Erfurt, BA \\ $\operatorname{Max}$ A. Heirich, PhD
}

Information is presented from a multiplant study of interventions to improve cardiovascular health among employees. Risk factors targeted were high blood pressure, obesity, and cigarette smoking. The study utilized on-site wellness counselors who periodically contacted all employees identified through screening as having one or more of the three risks. Use of a structured protocol for client outreach resulted in the large majority of clients being seen in follow-up during the three-year intervention period. Drawing from caseload experience and from various theoretical perspectives, seven engagement strategies were used to help guide at-risk clients toward successful behavior changes to reduce health risks. Results showed that of the three at-risk groups, clients with high blood pressure were most likely to be seen in follow-up, and most likely to begin a risk reduction program. For the overweight and smokers, clients seen three or more times were more likely to begin a weight-loss/smoking cessation program than clients seen less often. Frequency of follow-up showed a positive relationship with risk reduction for all three risks, in samples of employees rescreened at the end of the intervention period, but the relationship was not statistically significant for smoking cessation.

\section{INTRODUCTION}

The aging of the U.S. population and continuing increases in the cost of health care, much of it paid by the employer, have combined to increase corporate interest in methods for preventing or reducing disease. The worksite

The work reported in this article was supported jointly by grant HL33099 from the National Heart, Lung and Blood Institute, U.S. Department of Health and Human Services, and the General Motors-United Auto Workers National Joint Committee on Health and Safety. Special thanks are due to Wellness Counselors Victoria Cameron, Cydne Friday, MA, Barbara Konopka, PhD, and Doris Newton, RN. We also wish to thank the following: Liliane Calati, RN, Susan Czapski, RD, MEd, Rebecca Goodman, BA, Patricia Strauch, BS, and Mary Uzdale.

The authors are with the Worker Health Program, Institute of Labor and Industrial Relations at The University of Michigan.

Address reprint requests to Andrea Foote, $\mathrm{PhD}$, Worker Health Program, Institute of Labor and Industrial Relations, The University of Michigan, 1111 E. Catherine, Ann Arbor, MI 48109-2054. 
offers special advantages as a location for risk-reduction and health promotion programs. It is a bounded community in which there are daily interactions and standardized forms of communication.

These aspects of worksites make them particularly good locations for wellness programs. Not only can a worksite program address environmental changes that may improve health, but also, unlike community-based programs, at the worksite one can screen virtually the entire target population for specified health risks, and address interventions toward those people identified. It is then possible to measure how many of those with specified health risks participate in risk-reduction programs, as well as to assess progress over time in reduction of risks and ultimately health changes as measured through company-paid health care costs. ${ }^{1-3}$

The published research on worksite wellness programs has largely focused on program impact among participants, rather than impact on the total employee population at risk. ${ }^{+-8}$ Little attention has been paid to methods of involving a large proportion of people with targeted risks in risk-reduction programs. Programs with low participation of the at-risk population, even if they are highly successful for participants, will have little impact on overall health risk levels.

Some program descriptions do report participation rates, many of which are quite low. ${ }^{9-12}$ Reports of high rates of participation are found for worksites with small numbers of employees, in which participation is easier to obtain, ${ }^{13-1.5}$ and for programs that did not target specific high-risk groups. ${ }^{16-19}$ Competitions have shown mixed success in achieving high participation for targeted risk-reduction programs. 11.210 .21

Follow-up monitoring and counseling have received some attention in the research literature as a means of achieving health risk reduction in at-risk individuals. Most of the studies have been focused on hypertension control, ${ }^{22-24}$ but there is also evidence for the efficacy of follow-up with obese clients, ${ }^{25}$ and with substance abuse clients. ${ }^{26}$ Two studies have shown improvements as a result of follow-up which were later lost after follow-up contacts ceased. ${ }^{27-2 h}$ No studies were found that examine follow-up counseling as a method for inducing or engaging people with health risks into risk reduction activities.

\section{OVERALL STUDY DESIGN}

This article reports data from a study designed to examine methods for increasing participation in risk-reduction and health promotion activities at the worksite and to evaluate the effectiveness of these activities in reducing specific health risks (high blood pressure, cigarette smoking, and obesity). The study was conducted from 1985-1988 in four manufacturing plants. All were large (ranging in size from 1,500 to 3.000), and employed a workforce that was predominantly male, blue collar, two-thirds white, with an average age of about 40 years.

In 1985, all employees in the four plants were offered a voluntary wellness screening to check for the prevalence of smoking, high blood pressure, and obesity. Blood pressure was measured three times, using standard mercurymanometers, and blood pressure treatment status was obtained. Employees with 
two out of three elevated readings $(160 / 95 \mathrm{~mm} \mathrm{Hg}$ or higher) or currently under a doctor's care for hypertension were placed in the follow-up caseload for hypertension. Employees with readings of 140/90 or higher (but below 160/95 and not under treatment) were monitored regularly, and encouraged to see a physician for further evaluation.

Employees who reported smoking cigarettes were placed in the follow-up caseload as smokers, and employees who were $20 \%$ or more overweight (using the 1959 Metropolitan Life Insurance weight tables) were placed in the followup caseload as overweight. The 1959 tables were used in preference to the more recent tables to facilitate comparison with previous studies. Use of the earlier tables increased the numbers of people identified as at-risk, since the more recent tables specify higher ideal weights, but had no other relevance. Of the more than 7800 employees screened at the four plants (about $80 \%$ of the total work force of each plant), $44 \%$ were identified as smokers, $19 \%$ had high blood pressure, and $34 \%$ were overweight.

At two of the four plants, the program intervention included wellness counselors who worked in the plants during the three-year study period. These two sites are the focus of this report. The other two plants tested models that did not utilize counselors. Program descriptions across all four study sites are reported elsewhere. ${ }^{2 y}$

At these two sites, follow-up was used with clients identified as having any of the three specified health risks, in order to engage them into risk reduction activities and to support health improvements. It was hypothesized that the follow-up contacts provided by the wellness counselors would significantly increase both participation in risk-reduction activities, and subsequent reduction of the risk, in comparision with the two plants testing wellness program designs that did not include wellness counselors. This hypothesis was confirmed, as reported elsewhere. ${ }^{20}$

This article examines more carefully much of what actually occurred during the follow-up contacts between counselors and clients. The contents of the follow-up contacts are described as a set of seven engagement strategies utilized by the wellness counselors, and examples are provided of how each strategy was used.

In addition, the article provides a further test of the hypothesis that these follow-up contacts facilitate risk reduction, by comparing clients who received more vs. fewer follow-up contacts. During the study period, the wellness counselors maintained records of their contacts with clients. These data are used to compare the effectiveness of the follow-up at reaching different groups of clients, and engaging them into behavior change activities. At the end of the study in 1988, random samples of employees were rescreened to identify changes in risk status, and a comparison of results by amount of follow-up received is presented for these rescreened samples.

In summary, this article has three objectives: (1) to describe the engagement strategies used by the counselors during follow-up contacts with clients having health risks, (2) to examine the numbers of follow-up contacts achieved for the different target groups, and (3) to compare clients who received varying numbers of follow-up contacts in terms of initiation of risk reduction activities, and actual reduction of risks. 


\section{METHODS: REACHING CLIENTS IN FOLLOW-UP}

Each of the two plants had two wellness counselors during the three-year study period, both working about three-quarters time, for a full-time equivalent staffing of 1.5 counselors. The counselors' tasks were (among other things) to contact all of the employees identified as hypertensive, overweight, or cigarette smokers, and assist them to move through a behavior change process from contemplating change, through taking action to change, and maintaining change.$^{30}$

Each client at risk was to be contacted about once every six months. Generally, a letter or postcard was sent to the client's home asking him/her to come to the wellness office for a follow-up visit. The counselors then called the clients who did not respond, and tried to establish a day and approximate time the client would agree to come in. Clients still not seen were contacted at their work station through in-plant mailings, telephone, or through their supervisor, and asked to come to the wellness office on their break, or at the convenience of their supervisor or work schedule. Finally, the wellness counselors occasionally moved their work location onto the plant floor in order to increase accessibility, and notified nearby departments of their presence during that day.

Participation in follow-up was voluntary; clients who asked to be removed from the program (a very small number) were not contacted further. Failure to respond to outreach was not by itself defined as refusal, and clients who refused were not removed from the target population (some refusers eventually became engaged) nor from the analysis. The analysis includes all employees identified as at-risk during screening.

The follow-up contacts provided the opportunity for the wellness counselors to assist the client in decision-making pertinent to risk reduction and health promotion behaviors, and to engage the client into a program aimed at behavior change. The wellness counselors used a number of data sources for determining how to approach clients. These included information on the client's health risks; self-reported intent to change risks; last recorded weight, blood pressure readings, and smoking status; participation in risk-reduction programs; and the nature of the client's last contact with the wellness program.

Once clients began a risk-reduction program, follow-up contacts were used to monitor and support progress, assist in problem solving, identify and deal with relapse, and help clients begin to address other health risks or health improvements. In many cases reengagement was necessary, as clients dropped out or reverted to former behaviors. Thus, engagement must be seen as a process which is continued each time a client is seen in follow-up.

\section{METHODS: DESCRIPTION OF ENGAGEMENT STRATEGIES}

One objective of the study was to codify inductively the strategies that the wellness counselors used to engage clients into health improvement activities. Two procedures were used to do this. First, focus group meetings were held with the wellness counselors, about once a month during the study period, to review progress and compare results. Second, the literature on behavioral counseling was reviewed, and theories relevant to the engagement process were identified. 
The literature reviewed covers a wide range of approaches used in behavioral counseling, including protection-motivation theory, cognitive-restructuring, conflict theory, stress inoculation theory, interpersonal influence theory, and social learning theory. ${ }^{31-411}$ These sources detail specific techniques employed by professional behavioral counselors for catalyzing resources in the client's repertoire and for developing requisite skills for goal attainment.

Extrapolations have been made from these works in order to provide a context for the engagement strategies that were reported by the wellness counselors. However, it is important to note that the tasks of the wellness counselors are not the same as those of professional therapists. The wellness counselors serve to assist clients in the decision-making process that the clients undergo when confronted with health threats.

This literature review and discussions with the wellness counselors resulted in the identification of seven strategies or approaches used in engaging employees as participants in wellness activities. These approaches are not, in general, used separately; rather, they blend one into the other depending upon the client case history and the interaction that develops between client and counselor. Each approach is part of a process designed to support and nurture clients to a point where they can make informed decisions about their health, take action on those decisions, and maintain healthier behaviors. By providing clarity in ambiguous and confusing situations, the wellness counselor fosters a helping relationship that can assist the client to reduce barriers to a healthier lifestyle.

The seven strategies identified are the following:

(1) The Accepting Counselor Approach: Establishing Trust

(2) The 1-2-3 Approach: Building Sequential Strategies

(3) The Relative Risk Approach: Building on Success

(4) The Conflict of Intent Approach: Processing Ambivalence

(5) The "It's My Job" Approach: Dealing with Resistance

(6) The Personal Contract Approach: Negotiating Agreements

(7) The Fear Approach: Breaking Through Denial

Each strategy is discussed in detail below, including a review of relevant behavioral theories supporting the strategy, and examples of how the strategy was used by the wellness counselors in the study.

\section{Establishing Trust: The Accepting Counselor Approach}

This is a core strategy used in all interactions with clients, regardless of whether other strategies also are used. The accepting counselor approach embodies the concept of social or referent power, a major determinant for inducing genuine internalized changes in attitudes, values, and decisions. ${ }^{31.38 .41}$ The counselor demonstrates a sense of genuine caring for the client as a person, ${ }^{42}$ bolsters the client's sense of self-esteem, ${ }^{4.3}$ and is receptive to the client's specific situation and needs. This is accomplished by actively listening to the client's point of view and empathizing with his or her feelings.

The counselor's position as a source of warm regard and acceptance makes it possible to facilitate both positive and negative disclosures from the client. 
The negative disclosures are used to identify barriers to change and solutions which can overcome them. Positive disclosures are used to identify the client's personal strengths and accomplishments and to enhance the client's sense of self-esteem. Improvements in self-esteem have been shown to be effective in facilitating changes in health behaviors. ${ }^{44}$ This process acknowledges the importance of the client's beliefs, self-referent thought, symbolic processes, and social norms as determinants of behavior ${ }^{36.45}$ It requires that the wellness counselor think with rather than for the client. ${ }^{46.47}$

For this approach to be effective, the counselor provides feedback specific to the goals of the program. Clients receive spontaneous, caring acceptance (including expressions of empathy, optimism, and reassurance), even at times when they reveal personal weaknesses and shortcomings, except when they fail to make a sincere effort to live up to their commitment to reduce risks. Clients are guided by the counselor's specific feedback (which must be given in a nonthreatening way) to abide by the behavioral standards implied in the clients' prior decision to modify their risk status. ${ }^{39.48}$

If the counselor makes no demands on the client to adhere to the risk reduction behaviors the client selected, then the relationship between the counselor and client will continue to be warm but quite ineffectual. These demands can be either explicit or implicit, but the wellness counselor must be specific about what is going to happen, obtaining the client's commitment to carry out agreed tasks, and sticking with the client until the intended goals are achieved, as shown in this example.

During screening at one plant, one of the employees was found to have extremely high blood pressure and was hospitalized and put on sick leave for six weeks. When he returned to work I got in touch with him to see how he was doing. During our talk it came out that this was his first experience with hospitals and that he associated hospitals with death. It had been a very frightening experience for him! Once he talked with me about his fear and saw that I was not going to criticize him or minimize his feelings, it seemed easier for him to ask my help in following his doctor's advice to avoid similar experiences in the future. At that point we began looking over some of our materials on weight loss and low salt diets.

\section{Building Sequential Strategies: The 1-2-3 Approach}

This strategy is intended to guide clients along a decision path from a position of no action or interest to one where at least some action is being taken or being considered. During the follow-up visit, the counselor uses any disclosure about the client's dissatisfaction with his or her current health status to influence the client to discuss changing his/her behaviors, by participating in a specific risk modification program.

For example, if a client indicates intent to change but is reluctant to commit to a formal program for risk reduction, the counselor reviews the available alternatives and works with the client to select a course of action (the first step in the 1-2-3 approach). The review presents the client with the available options (which will vary from program to program). In step 2, the counselor maintains 
periodic contact with the client according to an agreed upon time schedule. If the approach selected was not successful, the counselor reviews the situation with the client and assists the client in a search for different approaches that might more appropriately match his/her needs (e.g., moving the client from a self-help approach to more formalized instruction). This is step 3.

It is important for the counselor to think with the client and not for the client during these steps. The counselor thus helps the client move gradually from no action to a belief that he or she can take effective action and then to actually making positive changes, as shown in this example.

\begin{abstract}
Recently, I saw a male employee who had expressed an interest in quitting smoking during the plant-wide health appraisal, to see if he would be interested in joining one of our organized stop smoking programs. He said that he didn't need any help from me as he was sure that he could do it on his own. I asked him if two months would be an acceptable amount of time to meet with him and check on his progress. He agreed to meet in two months and to seriously consider joining a group program if he was not successful in quitting on his own. I provided him with self-help materials, went over them to see if he had any questions, and arranged a date and time for him to return to the office. I called him two months later and he came in for a visit, but was still smoking. We discussed some of the reasons why it was so difficult for him to stop on his own and how the group program might more effectively address those problems. He signed-up and participated in one of our next classes.
\end{abstract}

This example demonstrates a most effective way to use self-help materials. Pamphlets are not just handed out, they are completely discussed with the client to make sure the client understands what needs to be done, and most importantly, to set a follow-up appointment for evaluating the self-help program and considering other strategies with the client, if necessary.

\title{
Building on Success: The Relative Risk Approach
}

This approach is used with clients who have met with some success in changing risky behaviors but who still have additional health risks. The counselor praises the client for the previous successes and tries to build on that success in working with the client to reduce other risks or build a healthier life style. In a sense, this is the reverse of the 1-2-3 Approach; it builds on success, whereas the former tries to build on failure.

In this situation, the counselor shows support through accepting the client's accomplishments and sharing in his or her sense of achievement and control. Once the client sees the counselor as a supportive person, it becomes easier and more effective to use this position as a health expert. ${ }^{35.38 .39,47}$ The key here is to use the clients' recent success to enhance their sense of self-efficacy. This, in turn, strengthens their motivation to continue toward the more general goal of improved health ${ }^{33.34}$ Once the counselor feels that the client is showing signs of a firm sense of self-efficacy, he/she gently begins to discuss the remaining health risks that the client may have. The counselor points out that reducing one risk 
has placed the client in a healthier position. but that the remaining risks still pose a threat and also should be reduced.

This approach is also used preventively, to help clients develop a lifestyle plan geared to avoiding the development of further risks (e.g., improved nutrition, increased physical exercise).

One employee, after several visits to our office about his high blood pressure, finally decided to see his doctor. After going on treatment, his blood pressure was brought under control. He came into the office and was very proud of the fact that he had done something positive about his health. He had taken action and it had worked. I shared in his excitement over the accomplishment and congratulated him on a job well done. At this point, I gently began to bring up the fact that he was still at risk because of his smoking. I pointed out that he had shown a real interest in taking care of his body by seeing a physician about blood pressure. that this was just the beginning, and that quitting smoking would improve his health status and provide long-term benefits. We went over some of our self-help materials for stopping smoking and set up a date to get in touch and see how he was doing. He reported one month later that he had quit smoking.

The shift from congratulating the client to focusing on other areas that need improvement needs to be gentle and smooth. Many clients, especially those with multiple risks, will be concerned about the counselor making too many demands of them. In fact, an important aspect of the counselor's job is to assure that the client does not try to do too much too fast, and to act as a guide by remaining mindful of the other (nonhealth specific) demands that exist in the client's lives. When health risk target behaviors are prioritized and appropriate time lines established, the client remains more in control.

\section{Processing Ambivalence: The Conflict of Intent Approach}

This approach is used with clients who have made repeated verbal or written commitments to initiate some action, but who repeatedly fail to follow through. The counselor points out this history to the client, and engages him or her in a discussion of why this has occurred. In addition to discussing various practical and real barriers such as time and financial constraints which could limit program participation, the counselor attempts to raise the client's awareness about any internal barriers to taking action.

This process attempts to uncover what Janis and Mann ${ }^{35}$ have referred to as decisional conflict. Decisional conflicts involve opposing tendencies within the client to accept and at the same time reject a given course of action. It is important for the counselor to realize that the client's hesitation, vacillation, feelings of uncertainty, and expressions of anxiety, shame, or guilt are a direct result of these internal conflicts. On the one hand, the client is concerned about the losses that might result from a selected course of action (including the cost of not living up to prior commitments). On the other hand, the client is concerned that his or her reputation and self-esteem as a competent person are at stake. The more severe the anticipated losses, the greater the stress and resultant indecision toward participating in behavior change programs. ${ }^{38}$ 
In the case of defensive avoidance, the client may attempt to escape the conflict by procrastinating, constructing wishful rationalizations, remaining selectively inattentive to corrective information, or shifting responsibility to someone else. ${ }^{35}$ In this situation, a client may attempt to shift responsibility to the counselor rather than himself. In the case of hypervigilance, the client may attempt to seize upon any solution that promises immediate relief from the conflict. The counselor needs to be wary of the client's intentions to select a particular health improvement program that appears unsuited to the client's needs. The counselor's own assessment of the client should indicate a similar program selection in order to prevent the client from setting himself up for failure.

This approach is thus different from the 1-2-3 Approach, which supports clients' selection of a strategy that the counselor thinks might be unsuccessful, when the client has a clear direction and is ready to act. For some clients it may be more productive to allow the client to vacillate a while longer in indecision than to allow him or her to experience failure and the resultant loss of selfesteem and self-efficacy. ${ }^{34.38}$ When the counselor responds nonjudgmentally, clients begin to recognize that they really do wish to improve their health (i.e., the costs of not taking action are higher than the costs involved in taking the action). When this recognition emerges, the counselor will be in a better position to support the client in taking a more definite approach to action.

The counselor uses his or her legitimate role as a representative of the wellness program and as an accepting helper to confront the client about breaking his commitment to take action, to question his change of mind, to empathize with the difficulties and stresses involved with such a decision, and to emphasize concern about what this may mean for his overall health and well-being. While the counselor is empathetic about the client's reasons for not following through she also is firm in reminding him that the choice to do something about his health was a good one and that choosing not to participate was not.

The following example describes a use of this strategy, but in a situation where the client was approached with too little regard for the stressful situation that the conflict placed on the client and with too much focus on the rational (contract oriented) agreement that had been made.

I had an employee who came into our office every Friday to have his blood pressure checked. He is hypertensive, $63 \%$ overweight and a smoker. For at least four months he had been promising to lose weight and quit smoking-his doctor had been on his back - he wanted to do it and knew he had to do it. At a sign-up session at the plant, he put his name down for both weight loss and stop smoking classes that were to start the next week. He didn't show up at either program. On his next visit to our office I confronted him about not showing up at either program. I firmly asked him when he was going to start taking his health seriously. Very humbly, he promised to attend the weight loss program and promptly left the office all geared up to start the class. No more than five minutes later he was back in the office in a rage. Who was I to tell him what to do? He was not going to attend any programs, he was fine the way he was, etc. . He was screaming at me during this entire time-I tried to calm him but to no avail; he left the office very outraged. He will no longer come into the office if I am there but does stop by when one of the other counselors is there. 
Confrontations such as that in the example above can and do happen even with a long-standing relationship with the counselor. There are a number of reasons why the employee might get angry, including guilt, or feeling overwhelmed or overloaded, and some of these reasons are out of the counselor's control. In addition, there may be issues confronting the client which have nothing to do with health behaviors, and which for the moment are overwhelming the client.

In this case an alternative strategy should be taken to provide the client with support and guidance. Depending upon what is facing the client, the best choice may be to put health risk issues on hold until the more overpowering issues can be resolved. The primary goal is to maintain a healthy, supportive relationship with the client. In time, if the trusting relationship is maintained, the counselor may be able to guide the client into a better position to address health improvement choices more effectively.

\section{Dealing With Resistance: The “It's My Job" Approach}

This is an effective approach to use when a client becomes defensive about numerous attempts to encourage him or her to participate in a wellness activity, and asks, "Why are you bothering me?" The counselor emphasizes her legitimate role by pointing out that helping people to improve their health is her job, and that there is strong evidence that wellness activities benefit people's health. The counselor attempts to provide the client with a perception of the counselor as an expert with a legitimate role. ${ }^{31,49.50}$

This approach draws not only an expert authority, but bureaucratic authority. In a work setting, everyone has his job, and is expected to do it. This strategy connects the client-counselor contact to another reality (separate from health issues) - the reality of work responsibilities. Many clients who feel they do not require a wellness counselor will respond positively when this connection is made.

From an organizational point of view, this particular strategy also focuses the counselor's attention on his/her proper tasks, and discourages him from taking the easy way out when dealing with difficult clients. When clients respond negatively or are resistant to coming in for a visit, counselors may be tempted to count them as "refusals" and drop them from the caseload. By putting the tasks into an organizational context rather than a personal one, the possibility of developing or continuing interactions with the client is maintained. The strategy can help to defuse anger and allow the client to be approached again. When used only by itself, this approach keeps the door open for future contacts but does not move the engagement process forward.

As with the other approaches, the counselor avoids giving the client any indication that he/she thinks less of the client as a person because the client is not taking action to reduce important health risks. By empathizing with the client's difficulties and indecisions, the counselor makes it possible for the client to see the counselor as a supportive resource doing her job. This can set the stage for helping the client work out the best plan for health improvement, given the limitations the client faces, as described in the following example: 
An employee came into the office one day acting very indignant about receiving a post card at home about his blood pressure. He wanted to know why he was being bothered. especially since he knew that his blood pressure was normal. After pointing out that we had not seen him in over a year, had no idea what his pressure was now, and that we simply wanted to check with him about his current health status, he sort of cooled down. Later we discussed his smoking habits (three packs a day) and that my job was to help as many employees as possible to lessen their chances of getting heart disease. He softened his tone and said that he would think about giving up smoking or at least cutting down a little. In the end, he agreed to get in touch with me when he thought he was ready to quit.

This approach, is very similar to the accepting counselor approach, with the addition that contacts with employees are made not only because the counselor cares but because that's what she is hired to do. Even the most adamant of clients seem to understand and relate to job responsibilities as a good reason for counselors to contact them.

\section{Negotiating Agreements: The Personal Contract Approach}

This approach is used when a client has decided on a course of action, but requires additional guidance, structure, or support to plan how best to achieve his or her goal and to successfully follow through with the appropriate actions. Written contracts have been shown to be effective in helping clients change their behaviors and more importantly (at least for the duration of the contract) to sustain the changes. ${ }^{51-54}$ The counselor works with the client to write out an agreement or contract, specifying each action the client has agreed to undertake, along with a start-up date for each action, a follow-up date, and any rewards the client might identify as useful reinforcements for follow-through.

This process clarifies the relative responsibilities of the counselor and the client. ${ }^{55}$ Through acceptance of these responsibilities, the formal agreement tends to be a more powerful motivator than a private resolution or a vague intention to change behavior. Contracts do this by establishing reinforcements for intended actions. They also encourage compliance, because in mutually signing a contact the client establishes partial control over impulsive behavior by making agreements with another individual-the counselor. ${ }^{53}$

One employee I worked with was hypertensive, overweight, and a smoker. We discussed which risk he wanted to work on first and he decided to take a stop smoking class and successfully completed it. Afterwards, due to his success in the stop smoking program he decided that he wanted to take a weight loss program. Unfortunately, he gained weight instead of losing it and decided to wait awhile before attempting to lose weight again. After a few months the employee was asked to return to the office for a blood pressure check and I learned that he was not only still overweight but had started smoking again. $\mathrm{He}$ said that he was interested in both stopping smoking and losing weight but could not decide which risk factor to change first. After a brief discussion it became apparent that he needed a little more structure than before, so we we drew up an agreement for him to stop smoking first, and later to lose weight. A week 
later, he returned to the office and said that he had changed his mind and wanted to lose weight before quitting smoking. The contract was rewritten. When he returned for a follow-up contact he had lost weight and was still losing. At the next follow-up contact we realized that his original weight loss goal was not realistic so we once again altered the contract to accommodate the circumstances.

The agreement or contract does not have to be an immutable document. Changes can be made at any time to accommodate the needs and particular situations of the client. It is important to specify clearly the negotiated goal, detail the necessary responsibilities, break the required behaviors into achievable and observable components, make sure that reinforcements commensurate with the effort involved in the behaviors are delivered promptly, and if appropriate, provide a description of what will happen if the client fails to follow through with the agreement. ${ }^{32.53 .55,56}$

By minimizing ambiguity through such an agreement, and actively working with the client on deciding the content of the contract, the wellness counselor can maintain an effective working relationship with the client. People undergo a lot of stress whenever they are trying to arrive at or to implement a decision that involves short-term deprivation to attain long-term goals. Maintaining contact with clients and helping them to proceed beyond these stressful times, no matter how slow the progress, is always preferable to holding them to a contract that may not be realistic given the problems they face.

\section{Breaking Through Denial: The Fear Approach}

This approach is only used as a last resort. There is considerable debate in the literature about the merits and dangers of using fear arousal techniques. Nevertheless, it is used fairly widely by risk reduction counselors when all else has failed. The work of Janis and Feshbach ${ }^{57}$ points to the emotional interference and defensive reactions (e.g., avoidance of the recommended action) that may develop when the fear message is too strong. Such a situation can not only prevent a client from adopting the recommended action, but also can inhibit further productive interactions with the counselor in the future. Several more recent studies have further demonstrated that fear arousal has no direct positive effect on a person's intentions to adopt a recommended course of action, and they caution about the potential of inducing avoidant thinking on the part of the client. ${ }^{37.41}$

Given these findings, it is more effective to use fear arousing techniques to strengthen long-sustained cognitive structures (e.g. . beliefs in the severity of the danger) which have been shown to produce adaptive coping behaviors, rather than for arousing a more momentary emotional state of fear. ${ }^{5 \%}$ The counselor points out the consequences of not taking corrective action to alter risky behaviors, in the strongest terms possible, in order to communicate the seriousness of the risk(s), without going so far as to create an immobilizing or avoidant thinking state of fear. Once concern over the seriousness of the situation has been communicated to the client, the counselor presents alternative methods for avoiding the feared outcomes. 
One employee I worked with had been very hard to contact. Many attempts had been made to get in touch with him, phone calls, post cards, letters, with no response. Since his blood pressure had been recorded as quite high during the initial appraisal, I decided it might be best to visit him in person. His supervisor relieved him from the line, and showed him to the office where I was waiting to do a follow-up contact. The employee was somewhat angry and questioned me as to why I was calling him from his work, and that everyone was going to think that he had high blood pressure. I introduced myself to him and asked if he had received letters, post cards or telephone messages from the wellness office. His reply was that he didn't remember. I took his blood pressure and updated our information, then told him what his readings were-they averaged 190/120. At this point he still did not seem to realize the seriousness of the situation. I reached into my blood pressure kit and handed him a pamphlet called 'What to do in case of Heart Attack and Stroke.' I told him that everyone was right about his blood pressure, it was extremely high, so high in fact that he needed to go right to medical. He was shocked when the seriousness of the readings began to sink in and asked me to take one more reading. It was still very high. I let him know that his risky position was not permanent but that in order to change it he needed to take immediate and lasting action to get his pressure under control. He agreed to go to medical and later to take some time off for sick leave. He has since returned to work with his blood pressure under control, and now responds to our attempts to keep in touch.

It can be quite a shock for employees when they finally realize the gravity of their situation, and it is extremely important for the counselor to offer alternative actions that are not only immediately possible, but which are reasonable for the client to follow.

As pointed out earlier, these seven approaches, while separately discussed, are all part of a greater strategy for awakening a client's awareness and guiding him or her toward informed choices and actions that can improve health. The following example is given to demonstrate how such a combination of approaches can be linked together effectively to lead a client to successful behavior change.

An employee came into our office after the holidays, reporting trouble eating nutritiously and losing weight because his wife was out of town. I empathized with the difficulties of his particular position (Accepting Counselor) but reemphasized the importance of weight loss since his blood pressure tended to be on the high side. The employee was still reluctant to commit himself to any decisive course of action. I pointed out that he needed to find a way that worked for himself, even if his wife was not at home to prepare the types of foods he was supposed to eat, because the stakes were just too high (Fear Approach). However, since I didn't want to overdo the fear approach because it might work against my goal of motivating him to action. I decided to point out the successes he had enjoyed in the past. I reminded him how successful he had been at controlling his blood pressure and how his inaction at this time could take away that success, e.g., the higher his weight went, the more likely his blood pressure would also go up (Relative Risk Approach). Slowly, he began to realize the nature of his problem and decided to build upon his previous success and insure it by trying to keep his weight down. After identifying the problem, he was offered the choice of self-help, personal counseling with a dietitian, or a group weight loss program (1-2-3 Approach). No commitment was made during that 
session but the following day he came into the office with a self-generated diet. We have since been working well together to get his weight down and keep it there.

\section{RESULTS}

The engagement strategies discussed above were described and codified during the implementation of the study. They were not intended as experimental manipulations, but rather are statements of what the counselors did during follow-up interactions with clients. Consequently it is not possible to compare the effectiveness of one strategy with another: the study design will not support any such analysis. It is, however, possible to compare results across clients with different health risks, and to examine the effects of the number of follow-up contacts on participation in risk reduction programs and on reduction of targeted risks.

Table 1 shows the number of clients with the three targeted risks (high blood pressure, overweight by $20 \%$ or more, and cigarette smoking) at the two plant locations, and the percentage who were seen at least once in follow-up for the specified risk during the study period. Since over $80 \%$ of the plant populations participated in screening, these numbers represent over $80 \%$ of the employees with the targeted health risks. Most (over three-fourths) of the targeted groups

Table 1. Number of Clients with Risks in 1985, and Percent Seen in Follow-Up. 19851988, By Risk Factor and By Plant

\begin{tabular}{|c|c|c|c|c|}
\hline & \multicolumn{2}{|c|}{ Plant A } & \multicolumn{2}{|c|}{ Plant B } \\
\hline & $\mathrm{N}$ & $\%$ Seen & $\mathrm{N}$ & $\%$ Seen \\
\hline \multicolumn{5}{|l|}{ Type of Risk } \\
\hline High blood pressure & 437 & 95 & 228 & 89 \\
\hline $20 \%$ or more overweight & 657 & 76 & 335 & 84 \\
\hline Smokes cigarettes & 800 & 76 & 356 & 76 \\
\hline \multicolumn{5}{|l|}{ Number of Risks } \\
\hline One risk & 846 & 80 & 447 & 78 \\
\hline Two risks & 410 & 91 & 191 & 91 \\
\hline Three risks & 76 & 92 & 30 & 97 \\
\hline \multicolumn{5}{|l|}{ Risk Breakdown } \\
\hline High BP only & 101 & 96 & 82 & 80 \\
\hline Overweight only & 268 & 76 & 148 & 84 \\
\hline Smoker only & 477 & 79 & 217 & 72 \\
\hline High BP and overweight & 163 & 97 & 82 & 99 \\
\hline High BP and smoker & 97 & 97 & 34 & 94 \\
\hline Overweight and smoker & 150 & 82 & 75 & 80 \\
\hline All three risks & 76 & 92 & 30 & 97 \\
\hline
\end{tabular}

analysis of variance showed that differences by number and type of risk were significant for both plants, $p<.01$

- Two out of three BP readings of $160 / 96$ or higher, or under treatment for high blood pressure. 
were seen in folow-up by the wellness counselors, using the outreach strategies described above.

However, while follow-up participation was high in all groups, Table 1 shows some systematic differences in the rate of participation. The hypertensive employees were most likely to participate. Follow-up visits provide them with a means of monitoring their blood pressure levels.

The middle section of Table 1 shows that clients with more than one risk were more likely to participate in follow-up than clients with only one of the three risks. The advantage of including high blood pressure with overweight and smoking as targeted risks is shown in the bottom portion of the table. When high blood pressure is paired with another risk, the participation in follow-up rises. This not difficult to understand. People who smoke know that they smoke, and people who are overweight know that also. But the measurement of blood pressure requires expert help, for most people.

Table 2 shows the average number of follow-up contacts per client seen in follow-up, during the three-year study period. The top portion of the table shows that clients with high blood pressure were seen more often than the overweight or smokers. The middle section shows that clients with more than one risk were seen more often than clients with only one risk. Follow-up visits were particularly frequent for clients with both a weight and blood pressure problem (bottom

Table 2. Mean Number of Follow-Up Contacts per Client, 1985-1988, for Clients Seen in Follow-Up. by Risk Factor and by Plant

\begin{tabular}{lccccc}
\hline & \multicolumn{2}{c}{ Plant A } & & \multicolumn{2}{c}{ Plant B } \\
\cline { 2 - 3 } \cline { 5 - 6 } \cline { 5 - 6 } & $\begin{array}{c}\text { Number } \\
\text { Seen }\end{array}$ & $\begin{array}{c}\text { Mean Number } \\
\text { Contacts }\end{array}$ & & $\begin{array}{c}\text { Number } \\
\text { Seen }\end{array}$ & $\begin{array}{c}\text { Mean Number } \\
\text { Contacts }\end{array}$ \\
\hline Type of Risk' & & & & & \\
High blood pressure & 414 & 4.9 & & 202 & 4.8 \\
20\% or more overweight & 498 & 3.8 & & 283 & 3.9 \\
Smokes cigarettes & 608 & 2.4 & & 271 & 2.9 \\
Number of Risks & & & & \\
One risk & 677 & 2.5 & & 347 & 2.7 \\
Two risks & 375 & 4.4 & & 173 & 4.3 \\
Three risks & 70 & 3.5 & & 29 & 5.9 \\
Risk Breakdown & & & & 66 & 3.7 \\
High BP only & 97 & 4.5 & & 66 & 2.8 \\
Overweight only & 205 & 2.9 & & 125 & 2.2 \\
Smoker only & 375 & 1.8 & & 156 & 5.7 \\
High BP and overweight & 158 & 6.4 & & 81 & 3.7 \\
High BP and smoker & 94 & 4.1 & & 32 & 2.7 \\
Overweight and smoker & 123 & 2.3 & & 60 & 5.9 \\
All three risks & 70 & 3.5 & & 29 & \\
\hline
\end{tabular}

- Figures show mean number of contacts in which that risk was addressed.

' Figures show mean number of contacts per client, regardless of which risks were addressed.

Note: Analysis of variance shows that differences are significant for both plants by number and type of risk, $p<.01$. 
portion of Table 2). Weight loss is often a treatment for high blood pressure among the overweight, and a joint focus on both risks can be especially helpful in assisting clients to reduce the risks.

Tables 1 and 2 show that the majority of employees at risk can be successfully seen through an aggressive worksite follow-up program. Table 3 provides evidence on the effectiveness of these outreach and engagement strategies at getting the employees to undertake risk-reduction programs.

For high blood pressure, a risk-reduction program is defined as receiving treatment for the disease by a physician. Because treatment for high blood pressure is long-term, the measure used in Table 3 to define treatment participation is being under treatment at the most recent follow-up contact.

For weight loss and smoking, in contrast, participation in a risk-reduction program is usually short-term. Therefore the measure used in Table 3 is having undertaken a smoking cessation or weight loss program at the worksite at any time during the project period.

It should be clear that in this analysis we are not measuring compliance with treatment, for any of the three target groups. We are only measuring participation in an appropriate risk-reduction intervention.

Rather than dividing the client groups by plant location as was done in Tables 1 and 2, Table 3 divides them by number of follow-up contacts (1-2 vs. 3 or more) during the three-year follow-up period. We are unable to include people with no follow-up contacts, because without follow-up contacts we have no information on whether they participated in a risk-reduction intervention.

The top portion of Table 3 shows that $88 \%$ of the employees with high blood pressure entered treatment for hypertension, and there was no difference be-

Table 3. Participation in an Appropriate Risk-Reduction Intervention For Clients Seen in Follow-Up, by Number of Follow-Up Contacts, 1985-1988

\begin{tabular}{|c|c|c|c|}
\hline & \multicolumn{2}{|c|}{$\begin{array}{c}\text { Number of Follow-Up } \\
\text { Contacts }\end{array}$} & \multirow[b]{2}{*}{ Probability" } \\
\hline & $1-2$ & 3 or more & \\
\hline \multirow{2}{*}{$\begin{array}{l}\text { Clients with High BP in } 1985(N) \\
\text { Percent in treatment for } \\
\text { high BP at latest contact }\end{array}$} & $(291)$ & (325) & \\
\hline & $88 \%$ & $88 \%$ & ns \\
\hline \multirow{2}{*}{$\begin{array}{l}\text { Clients } 20 \% \text { or more } \\
\text { overweight in } 1985(N) \\
\text { Percent in a worksite weight } \\
\text { loss intervention, } 1985-1988,{ }^{\circ}\end{array}$} & $(442)$ & (339) & \\
\hline & $60 \%$ & $81 \%$ & $<.001$ \\
\hline \multirow{2}{*}{$\begin{array}{l}\text { Clients who smoked } \\
\text { cigarettes in } 1985(N) \\
\text { Percent in a worksite smoking } \\
\text { cessation intervention, 1985-1988 }\end{array}$} & $(583)$ & (296) & \\
\hline & $53 \%$ & $76 \%$ & $<.001$ \\
\hline
\end{tabular}


tween those who were seen once or twice and those who were seen more often. In contrast, those who were overweight and those who smoked cigarettes did show significant differences depending on the number of follow-up contacts. Clients seen more often were significantly more likely to begin a worksite riskreduction program that those seen only once or twice. Of those seen three times or more, $81 \%$ of the overweight and $76 \%$ of the smokers began a risk-reduction program, compared with $60 \%$ of the overweight and $53 \%$ of the smokers who were seen once or twice.

The data shown in Table 3 are based on the follow-up records maintained by the wellness counselors, and therefore tell us nothing about what happened to the people who did not participate in follow-up. In order to examine changes in risk levels for all clients identified as at risk (including clients who did not participate in follow-up), we move to a different dataset. At the end of the three-year study period, random samples of employees at the plants were rescreened (with an $80 \%$ response rate), and risks re-measured.

Table 4 shows data from three subsamples of the rescreened employeesthose who were hypertensive at baseline screening in 1985, those $20 \%$ or more overweight at baseline screening, and those who smoked cigarettes at baseline screening. Analysis of variance is used to examine changes in the level of risk, comparing those with no follow-up contacts, those with one or two contacts, and those with three or more contacts.

For each subsample, the data show increased reduction in the level of risk with an increase in the number of follow-up contacts. The changes are significant for systolic blood pressure and weight, and nearly significant for diastolic blood pressure, despite very small numbers of people in the "no follow-up" groups.

Table 4. Change in Risk Factors, by Number of Follow-Up Contacts, 1985-1988, for Clients Rescreened in 1988

\begin{tabular}{|c|c|c|c|c|}
\hline & \multicolumn{3}{|c|}{ Number of Follow-Up Contacts } & \multirow[b]{2}{*}{ Probability } \\
\hline & None & $1-2$ & 3 or more & \\
\hline \multicolumn{5}{|l|}{ Clients with High } \\
\hline $\mathrm{BP}$ in $1985^{\circ}(N)$ & $(2)$ & $(46)$ & $(111)$ & \\
\hline Change in systolic BP, 1985-1988 & $+4.0 \mathrm{~mm}$ & $-2.7 \mathrm{~mm}$ & $-9.2 \mathrm{~mm}$ & $<.05$ \\
\hline Change in diastolic BP, 1985-1988 & $+7.0 \mathrm{~mm}$ & $-3.4 \mathrm{~mm}$ & $-6.9 \mathrm{~mm}$ & .06 \\
\hline \multicolumn{5}{|l|}{ Clients $20 \%$ or More } \\
\hline overweight in $1985(N)$ & (17) & (131) & $(175)$ & \\
\hline Change in weight, $1985-1988$ & $+2.2 \mathrm{lbs}$ & $-.3 \mathrm{lbs}$ & $-5.6 \mathrm{lbs}$ & $<.01$ \\
\hline \multicolumn{5}{|l|}{ Clients who smoked } \\
\hline Percent not smoking, 1988 & $16 \%$ & $19 \%$ & $21 \%$ & ns \\
\hline Change in no. daily cigs., 1985-1988 & -.8 cigs & -4.7 cigs & -5.6 cigs & ns \\
\hline
\end{tabular}

"Based on analysis of variance.

" Two out of three BP readings of $160 / 96$ or higher, or under treatment for high blood pressure. 
For cigarette smoking the changes are not significant, but are in the expected direction.

Because the number of follow-up contacts was not an experimentally manipulated variable, but rather reflects employees' interests or ability to participate in follow-up, multiple regression analysis was used to control for possible confounding effects of demographic variables (shown in Table 5). For each group of at-risk employees, measures of reduction in the identified risk are regressed onto five independent variables: number of follow-up contacts during the study period, number of risks (one, two, or all three), age, sex, and race (the last two measured as dummy variables). The number of risks was included as a predictor, in order to adjust for possible confounding effects of being seen for more than one risk. Results are shown as beta coefficients (or standardized regression coefficients), in order to be able to compare the relative effects of the five predictors.

The first two columns of Table 5 show results for the hypertensive employees. The number of follow-up contacts during the study period was the only one of the five predictors that showed a significant relationship to reduction in both systolic and diastolic blood pressure-the more the follow-up contacts, the greater the reduction.

The third column in Table 5 shows those people in the rescreened sample who were $20 \%$ or more above their ideal weight at initial screening in 1985 . The clients seen more often in follow-up had greater weight loss than those seen less often, and again this is the only variable of the five predictors that was related to weight change.

The final column in Table 5 shows the employees in the rescreened sample who smoked cigarettes in 1985. The number of follow-up contacts shows no relationship to the reduction in number of cigarettes smoked daily. Only age is related to smoking reduction; older people reduced their consumption more than younger ones.

\section{DISCUSSION}

This article has attempted to do something seldom possible within the constraints of journal articles: to describe in detail a substantial portion of a complicated intervention, as well as to report statistical results of the intervention. The constraints of limited space often mean that interventions conducted in the field (which are usually more complicated than laboratory interventions) can only be described as a "black box" through which subjects pass. The detailed workings of the box are not described. A large portion of this article has attempted to illuminate the box.

One may ask why the intervention was not simplified for research purposes, breaking it up into component parts and testing each sequentially. The answer is that the process is not amenable to being thus broken up-the whole is greater than the sum of its parts. It is doubtful that one would learn anything of importance by offering a wellness program that included only engagement strategy A, without B. C, and D (and subsequently offered only B, and so on), or by offering engagement strategies without any client outreach, etc. The components of the follow-up process are designed to work together. 
Table 5. Multiple Regression Equations Regressing 1988 Risk Level on Predictor Variables, for Three Groups of Clients Rescreened in 1988

\begin{tabular}{|c|c|c|c|c|}
\hline \multirow[b]{2}{*}{ Dependent Variahle $=$ Change In } & \multicolumn{2}{|c|}{ Hypertensive in 1985} & \multirow{2}{*}{$\begin{array}{c}\text { Overweight in } \\
1985 \\
(N=323) \\
\text { Weight, } \\
1985-1988\end{array}$} & \multirow{2}{*}{$\begin{array}{c}\begin{array}{c}\text { Smoked in } \\
1985\end{array} \\
(N=340) \\
\text { Cigs/ Day, } \\
1985-1988\end{array}$} \\
\hline & $\begin{array}{r}(N \\
\text { Systolic BP } \\
198.5-1988\end{array}$ & $\begin{array}{c}159) \\
\text { Diastolic BP } \\
1985-1988\end{array}$ & & \\
\hline \multicolumn{5}{|l|}{ Bcta Coefficients for } \\
\hline No. follow-up contacts, $1985-1988$ & $-.25^{\mathrm{b}}$ & $-.29^{\mathrm{h}}$ & -.12 & .02 \\
\hline No. risks (BP, overw't, smoking) & -.02 & -.04 & .07 & .01 \\
\hline Age & -.01 & -.01 & -.09 & $-.12^{\mathrm{a}}$ \\
\hline Sex (male) & .05 & -.02 & .05 & .03 \\
\hline Racc (white) & -.01 & .11 & -.05 & -.03 \\
\hline$R^{2}$ & .07 & .09 & .03 & .02 \\
\hline
\end{tabular}

" $p<.05$.

' $p<.01$.

Our recourse for this problem was to test different program models or designs, in different locations, each model including a set of interrelated activities. This article, however, has not compared results across the different models, but has examined the efficacy of one model at doing what it was designed to do: reach at-risk employees, engage them in risk-reduction activities, and reduce their risks. The comparison presented in this paper is not across different models, but across different groups of employees within the same model. Reports that examine and compare results across the other models may be found elsewhere. ${ }^{29.59} .60$

The data show that systematic outreach by on-site wellness counselors was effective in reaching the great majority of employees at risk. It is important to understand that this outreach included more than a periodic invitation (by mail, phone, or plant-wide news media) to participate. While employees had the right not to participate (and as can be seen from Table 1, some of them did not), failure of the employee to come to the wellness office for a visit was not in itself deemed a refusal. Follow-up outreach continued with the reluctant employees as well as with the eager ones.

Once the counselor achieved a visit with the client at risk, the strategies for engaging the client into a risk-reduction program were employed. The engagement strategies described above may be employed separately or in combination, depending on the client's specific situation and the counselor's assessment of that situation. Engagement is an on-going process, not an event that occurs once. Clients must continually be reengaged into wellness activities. Thus the engagement strategies described above are at the core of all follow-up contacts.

These strategies are used to facilitate the decision-making process that precedes participation in specific behavior change activities, and to support health improvements as they occur. The strategies are not substitutes for treatment or behavioral therapy through formal risk-reduction interventions. While some clients were subsequently able to take risk-reduction action on their own, with support from the wellness counselor, other clients utilized formal instructor-led interventions. 
Employees with high blood pressure showed the greatest response to the follow-up and engagement strategies. Almost all of them were seen in followup, and nearly $90 \%$ began treatment for hypertension. Rescreening data at the end of the study period showed that frequency of follow-up was associated with reductions in both systolic and diastolic blood pressure.

High blood pressure is the easiest of the three risk factors studied to control. While it requires medical treatment through a physician in the community, the data above as well as previous studies have shown that monitoring and counseling at the worksite can assist most hypertensives to keep their blood pressure under control. In the absence of follow-up counseling, however, treatment dropout is a major problem in the control of high blood pressure, and only $20-30 \%$ of identified hypertensives maintain their blood pressure in the normal range. ${ }^{27.28}$

The data also suggest that follow-up for blood pressure can be used as a strategy for engaging people with other risks. Interventions for smoking cessation and weight loss are in one respect easier than those for hypertension-they can be brought to the worksite in the form of weight loss and smoking cessation classes.

The difficulty is that (a) most employees who smoke or are overweight do not want to (or are not able to) take part in classes, and (b) classes typically show good short-term results but poor long-term results. The behavior changes required for stopping smoking and losing weight are in general more difficult to sustain than those required for maintaining blood pressure therapy, and yet the major modality for blood pressure therapy is long-term while the major modalities for smoking cessation and weight loss are short-term.

Introduction of regular follow-up counseling at the study sites resulted in over three-quarters of the smokers and the overweight being seen in follow-up. Of those seen three or more times, $76 \%$ and $81 \%$ of the smokers and overweight, respectively, began a risk-reduction program. In the rescreened samples the amount of follow-up was significantly related to weight reduction among the overweight, and there is a small but nonsignificant relationship to smoking cessation.

Results for smoking cessation were complicated by the fact that the corporation of which all of the study sites were a part adopted a new smoking policy during the first year of the study. Furthermore, during this time period (19851988) there was considerable public attention to smoking, and the Surgeon General's report on the effects of sidestream smoke was released. These events appear to have had a stronger impact on smoking cessation than did follow-up counseling, because there was a significant reduction in prevalence of smoking at all four of the study sites. While the quit rates were a little higher for clients who received follow-up counseling, further study is needed to separate the effects of follow-up outreach and counseling from the effects of general educational campaigns and policy changes.

\section{IMPLICATIONS FOR PRACTICE}

The data described above support the efficacy of worksite follow-up for engaging clients with health risks into risk-reduction activities and assisting them 
to make health improvements. These results are congruent with previous research reports ${ }^{24.28 .29}$ Analysis is underway examining the cost-effectiveness of this follow-up counseling. Previous research found that follow-up for high blood pressure was highly cost-effective. ${ }^{\text {II }}$

One important implication from the data above is that a multiple risk focus is more efficient than a single risk focus, particularly if one of the risks involves a physiological measurement that the client cannot make for himself. When clients come to the wellness office for a blood pressure or blood cholesterol recheck, the counselor can help them address their other risks as well.

While this report has not presented evidence comparing the effectiveness of the follow-up counseling model with other models of worksite wellness programs, the larger study from which this report comes does show that without followup outreach and counseling, the regular provision of health education classes does not produce the same amount of change in the targeted health risks, nor does a fully-staffed fitness center produce such change (paper in progress).

Perhaps the most important aspect of the follow-up model is that it is ongoing, for as long as the client is an employee at the location. With continuing counseling, today's nonparticipants may become tomorrow's participants; today's high risk cases may become tomorrow's lowered risks; and perhaps most importantly, tomorrow's relapsers will be identified the next day (i.e., at the next follow-up visit) and assisted to regain health improvements.

\section{References}

1. Gibbs JO, Mulvaney D, Henes C, Reed RW: Work-site health promotion: Five-year trend in employee health care costs. Journal of Occupational Medicine 27:826-830, 1985.

2. Bly JL, Jones RC, Richardson JE: Impact of worksite health promotion on health care costs and utilization. Journal of the American Medical Association, 256:3235$3240,1986$.

3. Blair SN, Piserchia PV, Wilber CS, Crowder JH: A public health intervention model for work-site health promotion. Journal of the American Medical Association 255:921926, 1986.

4. Leviton LC: The yield from work site cardiovascular risk reduction. Journal of Occupational Medicine, 29:931-936, 1987.

5. Bjurstrom LA. Alexiou NG: A program of heart disease intervention for public employees: A five year report. Journal of Occupational Medicine, 20:521-531, 1978.

6. Abrams AB, Follick MJ: Behavioral weight-loss intervention at the worksite: Feasibility and maintenance. Journal of Consulting and Clinical Psychology, 51:226-233, 1983.

7. Stunkard AJ, Brownell KD: Work-site treatment for obesity. American Journal of Psychiatry, 137:252-253, 1980.

8. Fielding JE: Effectiveness of employee health improvement programs. Journal of Occupational Medicine, 24:907-916, 1982.

9. Lowe JB, Windsor RA, Post KL: Effectiveness of impersonal versus interpersonal methods to recruit employees into a worksite quit smoking program. Addictive Behaviors, 12:281-284, 1987.

10. Jeffrey RW, Forster JL, Snell MK: Promoting weight control at the worksite: A pilot program of self-motivation using payroll-based incentives. Preventive Medicine, 14:187194, 1985. 
11. Davis KE, Jackson KL, Kronenfeld JJ, Blair SN: Determinants of participation in worksite health promotion activities. Health Education Quarterly, 14:195-205.

12. Gritz ER, Marcus AC, Berman BA, Read LL, Kanim LEA, Reeder SJ: Evaluation of a worksite self-help smoking cessation program for registered nurses. American Journal of Health Promotion, 3:26-35.

13. Stachnik T, Stoffelmayr B: Worksite smoking cessation programs: A potential for national impact. American Journal of Public Health, 73:1395-1396.

14. Brownell KD. Cohen RY, Stunkard AJ, Felix MRJ, Cooley NB: Weight loss competitions at the work site: Impact on weight, morale and cost-effectiveness. American Journal of Public Health, 74:1283-1285.

15. Tampson P: Franklin International: A facility based wellness program adapted to service a small white and blue collar population. American Journal of Health Promotion, 2:39-46.

16. Bowne DW, Russell ML, Morgan JL, Optenberg SA, Clarke AE: Reduced disability and health care costs in an industrial fitness program. Journal of Occupational Medicine, 26:809-816, 1984.

17. Metcalfe LL: Campbell Soup Company's Turnaround Health and Fitness Program. American Journal of Health Promotion, Fall:58-68, 1986.

18. Parkinson R: Participation: Keystone in health promotion evaluation. Corporate Commentary, November 1984; 1:30-35.

19. Spilman MA, Goetz A, Schultz J, Bellingham R, Johnson D: Effects of a Corporate Health Promotion Program. Journal of Occupational Medicine, 28:285-289, 1986.

20. Brownell KD. Felix MRJ: Competitions to facilitate health promotion: Review and conceptual analysis. American Journal of Health Promotion, Summer:28-36, 1987.

21. Klesges R, Vasey M, Glasgow R: A worksite smoking modification competition: Potential for public health impact. American Journal of Public Health, 76:198-200, 1986.

22. Logan AG. Milne BJ, Achber C, Campbell WP, Haynes RB: Work-site treatment of hypertension by specially trained nurses: A controlled trial. Lancet, 2:1175-1178, 1979.

23. Alderman MH, Stormont B: Work site vs. community based antihypertensive care: A controlled trial. Preventive Medicine, 8:123, 1979.

24. Foote A, Erfurt JC: Hypertension control at the work site: Comparison of screening and referral alone, referral and follow-up, and on-site treatment. New England Journal of Medicine, 308:809-813, 1983.

25. Perri MG, Shapiro RM, Ludwig WW, Twentyman CT, McAdoo WG: Maintenance strategies for the treatment of obesity: An evaluation of relapse prevention training and post-treatment contact by mail and telephone. J. Consult. Clin. Psych., 52:404413, 1984.

26. Foote A, Erfurt JC: Effects of EAP follow-up on prevention of relapse among substance abuse clients. $J$ Stud Alc, (in press).

27. Wilber JA, Barrow JG: Reducing elevated blood pressure-Experience found in a community. Minnesota Medicine, 52:1303-1305, 1969.

28. Erfurt JC, Foote A: Maintenance of blood pressure treatment and control after discontinuation of worksite follow-up. J Occup Med, 32:513-520, 1990.

29. Erfurt JC, Foote A, Heirich MA, Gregg W: Improving participation in worksite wellness programs: Comparing health education classes, a menu approach, and follow-up counseling. American Journal of Health Promotion, 4:270-278, 1990.

30. Prochaska JO, and DiClemente CC: Stages and processes of self-change of smoking: Toward an integrative model of change. J Consult Clinical Psych, 51:390-395, 1983.

31. French J, Raven B: The bases of social power, in Cartwright D (ed): Studies in Social Power. Ann Arbor University of Michigan Press, 1959.

32. Bandura A: Self-efficacy: toward a unifying theory of behavior change. Psychological Review, 84:191-215. 
33. Bandura A: Social Learning Theory. Englewood Cliffs, NJ: Prentice-Hall, 1977.

34. Bandura A: Self-efficacy mechanism in human agency. American Psychologist, 37:122$147,1982$.

35. Janis I, Mann L: Decision Making: A Psychological Analysis of Conflict, Choice, and Commitment. New York, The Free Press, 1977.

36. Meichenbaum D: Cognitive-Behavior Modification. New York, Plenum, 1977.

37. Shelton M, Rogers R: Fear-arousing and empathy arousing appeals to help: the pathos of persuasion. Journal of Applied Social Psychology, 4:366-378, 1981.

38. Janis I: Short-term Counseling: Guidelines Based on Recent Research. New Haven, Yale University Press, 1983.

39. Janis I: The role of social support in adherence to stressful decisions. American Psychologist, February:143-160.

40. Rippetoe P, Rogers R: Effects of components of protection-motivation theory on adaptive and maladaptive coping with health threat. Journal of Personality and Social Psychology, 52:596-604, 1987.

41. Tedeschi J, Lindskold S: Social Psychology: Independence, Interaction, and Influence. New York. Wiley, 1979.

42. Carkhuff R: The Art of Helping. Amherst, MA, Human Resources Development Press, 1972.

43. Brown D, Schulte A: A social learning model of consultation. Professional Psychology: Research and Practice, 18:283-287, 1987.

44. Quinlan D, Janis I, Bales V: Effects of moderate self-disclosure and amount of contact with the counselor, in Janis I (ed): Counseling on Personal Decisions: Theory and Research on Short-Term Helping Relationships. New Haven, Yale University Press, 1982.

45. Lazarus A: Has behavior therapy outlived its usefulness? American Psychologist, 32:550-554, 1977.

46. Brammer L. Shostrom E: Therapeutic Psychology: Fundamentals of Actualization Counseling and Psychotherapy. Englewood Cliffs, NJ: Prentice-Hall, 1968.

47. Okun B: Effective Helping: Interviewing and Counseling Techniques. North Scituate, MA: Duxbury Press, 1976.

48. Goldstein A: Relationship-enhancement methods, in Kanfer F, Golden A (eds): Helping People Change. New York, Pergamon Press, 1975.

49. Kerr B, Dell D: Perceived interviewer expertise and attractiveness. Journal of Counseling Psychology, 22:6-11, 1976.

50. Paradise L, Conway B, Zweig J: Effects of expert and referent influence, physical attractiveness, and gender on perceptions of counselor attributes. Journal of Counseling Psychology, 33:16-22, 1987.

51. Vance B: Using contracts to control weight and to improve cardiovascular physical fitness in Krumboltz J, Thoresen C (eds): Counseling Methods. New York, Holt, Rineholt and Winston, 1976.

52. Steckel S, Swain M: The use of written contracts to increase adherence. Hospitals, 51:81-84.

53. Kanfer F: Self-management methods in Kanfer F, Golden A (eds.): Helping People Change. New York, Pergamon Press, 1980.

54. Steckel S: Patient Contracting. Norwalk, CN, Appleton-Century-Crafts, 1982.

55. Lewis $\mathrm{C}$, Michnich $\mathrm{M}$ : Contracts as a means of improving patient compliance, in Barofsky I (ed): Medication Compliance: A Behavioral Management Approach. Thorofare, NJ, Charles B. Slack, Inc., 1977.

56. Melamed B. Siegel L: Behavioral Medicine: Practical Applications in Health Care. New York, Springer Publishing Co., 1980.

57. Janis I, Feshback S: Effects of fear-arousing communications. Journal of Abnormal and Social Psychology, 48:78-92, 1953.

58. Rogers R, Deckner W, Mewborn C: An expectancy value theory approach to the 
long term modification of smoking behavior. Journal of Clinical Psychology, 34:562566. 1978 .

59. Heirich MA. Cameron V. Erfurt JC. Foote A. Gregg W: Establishing communication networks for health promotion in industrial settings. American Journal of Health Promotion, 4:108-117, 1989.

60. Heirich MA. Konopka B. Erfurt JC. Foote A: Encouraging physical fitness among older employees. Fitness in Business, April:175-180, 1989.

61. Erfurt JC. Foote A: Cost-effectiveness of work-site blood pressure control programs. Journal of Occupational Medicine, 26:892-900, 1984. 